\title{
LA IMPORTANCIA DEL HIGIENISMO Y LA POTABILIZACIÓN DEL AGUA EN LA CIUDAD DE VALENCIA (1860-1910)
}

\author{
José Antonio Palomero González \\ Grupo de Economía del Agua. Universidad de Valencia ${ }^{1}$ \\ joseantonio_palomero@hotmail.com \\ Patricia Alvariño Serra \\ patricia.alvarino@hotmail.com
}

\section{RESUMEN}

El siglo XIX se caracteriza por numerosos cambios tanto a nivel social como estructural de la población: se produce un acelerado desarrollo urbano sin planificación y carente de servicios que da lugar a una mala calidad de vida y numerosas epidemias. Estos cambios tienen como resultado un nuevo movimiento, el Higienismo, que pretende mejorar las condiciones de vida de la población. En España, todas las reformas higiénicas se desarrollaron mediante los planes de Ensanche. Uno de los puntos clave de este pensamiento es el abastecimiento de agua potable como medio para evitar enfermedades. La ciudad de Valencia es un claro ejemplo de la importancia de este movimiento y cómo el abastecimiento de agua es un elemento clave en la mejora de la calidad de vida de las personas. ${ }^{2}$

Palabras clave: Higienismo; Potabilización; Valencia; Ensanche.

\section{ABSTRACT}

\section{The importance of Hygienics and Clean Water Treatment in Valencia (1860-1910)}

The nineteenth century is characterized by social and structural changes to the population: quick, unplanned urban development took place together with a lack of services that resulted in poor quality of life and numerous epidemics. These changes gave rise to a new movement, Hygienics, which aimed to improve the living conditions of the population. In Spain, all hygienic reforms were developed through Ensanche (urban expansion) Plans. One of the key points of this movement is a supply of clean water as a means to prevent diseases. Valencia is an example of the importance of this movement and how water supply is a key element in improving the quality of life. ${ }^{2}$

Key words: Hygienics; Water Purification; Valencia; Ensanche.

\section{INTRODUCCIÓN}

\subsection{Contexto histórico}

El siglo XIX destaca por sus numerosos cambios sociales y demográficos, cambios que se sucedieron en Europa y otros países desarrollados que permitieron pasar de un régimen demográfico antiguo al régimen demográfico moderno, el cual se caracteriza en elevadas tasas de natalidad y por un acusado descenso en la mortalidad. Este cambio de régimen tuvo como resultado un intenso proceso de crecimiento vegetativo de la población. España también es escenario de todos estos cambios: demográficos, sociales e

\footnotetext{
1 Avda. Tarongers S/N, 46022 Valencia, España.

2 Para la realización de este artículo se ha realizado una revisión bibliográfica en: la Biblioteca Valenciana - Nicolau Primitiu de Valencia; Biblioteca Nacional (Hemeroteca Digital Hispana); en el Archivo Municipal de Valencia; y en diferentes artículos científicos.
} 
industriales que suponen una ruptura con las formas de vida tradicionales y desarrollan un nuevo estilo de vida, aunque con cierto retraso en comparación al resto de Europa (Hijano Pérez, 2013).

Económicamente, España se encuentra más atrasada que el resto de Europa occidental debido a diferentes factores. En primer lugar, destaca la pérdida de las colonias de ultramar, que sume al país en una enorme deuda que lo hundirá económicamente. A este factor se deben sumar también las constantes guerras y una profunda crisis agraria durante la segunda mitad del siglo, que frenarán la recuperación económica del país. Una dificultad añadida al desarrollo económico se encuentra en la complicada orografía, que dificulta los transportes y comunicaciones entre ciudades. Además el factor social es un impedimento que dificulta el desarrollo económico: la sociedad está sumida en una estructura social rígida y desigual, que se magnifica en las ciudades creando barrios estructurados según niveles de renta (Hijano Pérez, 2013).

A principios del S.XIX, la población española se caracteriza por unas elevadas tasas de mortalidad, destacando unas elevadas tasas de mortalidad infantil, así como unas elevadas tasas de natalidad. La esperanza de vida es muy baja, situándose entre los 26,0 y 29,7 años (Dopico, F. y Rowland, R. 1990). A raíz de la primera industrialización, que se desarrolló a partir de 1830, la forma de vida tradicional en el campo se desestructuró. Los agricultores y gente del campo comienzan un proceso progresivo y constante de migración hacia las ciudades (migraciones interiores o éxodo rural), que se magnifica durante la crisis agraria de la segunda mitad del S.XIX. Estas migraciones internas son un agravante al proceso de litoralización de la población y despoblamiento interior, proceso que se inicia en la Edad Media y se consolida durante este siglo (Hijano Pérez, 2013).

El éxodo rural y el rápido crecimiento de las ciudades se mantienen constantes durante todo el siglo. Durante el periodo de 1830-1914, Europa alcanzó sus tasas máximas de desarrollo urbanístico (Bairoch, P. y Goert, G. 1986) de tal modo que el porcentaje de población viviendo en ciudades (de más de 5.000 habitantes) se duplicó durante el S.XIX tal y como se observa en la Tabla 1. La constante llegada de migrantes tiene como consecuencia que no haya planificación alguna en el crecimiento de la ciudad. En las ciudades se magnifica la profunda jerarquía social existente, coexistiendo barrios de clase burguesa y suburbios de clase obrera.

Tabla 1. Porcentaje de población viviendo en ciudades de 5.000 o más habitantes en España

\begin{tabular}{|c|c|c|c|c|c|c|}
\hline Año & $1800^{*}$ & 1830 & 1850 & 1880 & 1900 & 1910 \\
\hline Porcentaje (\%) & 17 & 17,5 & 18 & 26 & 34 & 38 \\
\hline
\end{tabular}

Fuente: Adaptado de Bairoch, P. y Goert, G. 1986. ${ }^{*}$ Datos aproximados.

\subsection{Higienismo, potabilización y abastecimiento de agua}

A mediados del S.XIX surge un movimiento técnico, cultural y jurídico enfocado en mejorar la calidad de vida de las ciudades: el Higienismo, en el cual los médicos y políticos de la época se unen contra la mala calidad de vida de las ciudades con el fin de luchar contra la propagación de las enfermedades y frenar el caldo de cultivo para la revolución social.

Los objetivos del movimiento Higienista son mejorar las condiciones de vida de los trabajadores y combatir las epidemias que asolaban las ciudades mediante el paradigma Higienista (equilibrio entre la ética y la pragmática) como forma de gobierno y como actuación destinada a prevenir y a remediar los males que afectaban al conjunto de la sociedad española (Alcaide González, 1999). Para ello, se centran en los siguientes aspectos: instalación de alcantarillado, tratamiento y abastecimiento de agua potable, instalación de alumbrado público, ordenación de las ciudades en calles bajo planes de ordenación (Ensanches) y la construcción de grandes vías para la aireación de la ciudad.

Los primeros casos documentados sobre el Higienismo se encuentran en 1848 con la publicación de la "Public Health Act" en Inglaterra por Edwin Chadwick, donde no sólo proponía una manera de combatir la alta mortalidad y las enfermedades epidémicas que estaban llevando a las ciudades industriales, sino un medio de neutralizar la radicalización obrera y la creciente agitación social (Ramos Gorostiza, 2014). Dos años más tarde, en Francia se promulgó la primera Ley Higienista. En esta época surgen los primeros estudios empíricos para ver la correlación entre las condiciones higiénicas en los servicios ur- 
banos y el grado de morbilidad de las enfermedades infecciosas en 1854 durante una epidemia de cólera por el doctor John Snow en Londres.

El movimiento Higienista español participó directamente, desde sus inicios, de los avances científicos en materia de higiene que se produjeron en Europa. Una de las causas que favorecieron dichos contactos fue la vuelta de los liberales exiliados a la vuelta al trono de Fernando VII en 1824, sin desmerecer las personalidades médicas que, desde el absolutismo, también contribuyeron a la consolidación de la doctrina higiénica (Alcaide González, 1999). Los Higienistas españoles se mostraron deudores del movimiento de Chadwick, convencidos de la influencia del ambiente en la salud y la moral y de la consiguiente necesidad de llevar a cabo actuaciones concretas que mejorasen la salubridad, priorizando el abastecimiento de agua abundante, la creación de redes de alcantarillado o la recogida de basuras (Ramos Gorostiza, 2014).

Las primeras aportaciones españolas sobre el Higienismo son: la monografía estadística de la clase obrera de Barcelona ( $2^{\circ}$ tomo de la Teoría General de la Urbanización) y el libro de Monlau Elementos de higiene pública, o el arte de conservar la salud de los pueblos de 1862 (Taberner, 1987). Otras muestras más tardías en las que se demuestra en qué se centra el movimiento Higienista español se encuentra en 1886 en la Revista de Obras Públicas donde surge una sección fija dedicada a este movimiento, titulada "Higiene Urbana" y posteriormente "Saneamiento y Ensanche de poblaciones". Este cambio de título en esta sección fija de la revista muestra la percepción española de cómo resolver el problema de la insalubridad y malas condiciones de vida en las ciudades: los Ensanches.

Los Ensanches no fueron sólo planes de ordenación para adaptar las ciudades a un aumento de población, sino supusieron la modernización y la transformación de las ciudades a la visión actual de ciudad. Esta experiencia fue peculiar del urbanismo del S.XIX y confirió al proceso de urbanización español formas únicas, distintas al norte de Europa (Cerdá, I., Barrera de Irimo, A. y Estapé, F., 1968; Solà-Morales, 1978; Carballo, B., Pallol, R. y Vicente, F., 2008).

Los aspectos innovadores de los Ensanches son: una idea de hacer ciudad donde la higiene, la ciencia, la razón, la igualdad prevalecen sobre los modelos anteriores de hacer ciudad; una nueva metodología: dirigir la proyección de la ciudad en vez de dejarla que surja por sí sola; nuevos instrumentos a la hora de ordenar el crecimiento de la ciudad y dotarla de servicios; y por último, la teoría de la idea racionalista de la ciudad entiendo el crecimiento como un proceso sujeto a proyectación, articulado con instrumentos y normativas operativas (Cerdá, et al., 1968; Solà-Morales, 1978).

Hay cuatro acontecimientos, relacionados entre ellos, sobre la teoría y la práctica de los problemas del planteamiento urbano y su solución: en 1854 Idelfonso Cerdá realiza el estudio previo al Ensanche de Barcelona; entre 1856 y 1867 Cerdá escribe el primer tratado moderno del urbanismo; en 1861 se aprueba la Ley General del Planeamiento (Ley de Ensanche de 1861), modificada en 1864 y en 1867; a raíz del Plan de Ensanche de Barcelona en 1859, surgen Ensanches posteriores. En España fue el Ensanche de Barcelona de Idelfonso Cerdá el precursor de un modelo que se extendió por todo el territorio (Cerdá, et al., 1968; Solà-Morales, 1978; Carballo, et al., 2008).

El Ingeniero de Caminos Idelfonso Cerdá es la figura más destacada del Higienismo español, siendo su innovación más potente la aproximación metodológica para el crecimiento de las ciudades. Esta metodología la aplica en el Ensanche de Barcelona que diseña y recoge en su libro "Teoría General de la Urbanización". Este libro define las vías y las intervías en función del análisis sistematizado de las exigencias técnicas de la circulación e higiénica, y la estructuración comarcal y regional de la viabilidad siendo estas las que definen el trazado retícula. Para Cerdá los problemas higiénicos de la ciudad no son un problema concreto que se puede abordar con soluciones parciales, hay que afrontarlo en su totalidad (Cerdá, et al., 1968; Solà-Morales, 1978; Colegio de Caminos Canales y Puertos de Alicante, 1991).

Uno de los puntos más importantes, y donde se centra la actividad Higienista, es el control del agua bebida (Barona Vilar, 2002). La higiene pasa a ser una cuestión social y comienza a analizarse bacteriológicamente el agua y a utilizarse cloro como desinfectante, lo cual resultó ser un factor clave en la mejora de la salud y el descenso de las tasas de mortalidad. Además la provisión de agua corriente tendría claros beneficios económicos, ligados a la prevención de la enfermedad, que compensarían con creces la inversión necesaria para llevarlas a cabo y que se dejarían notar también en las generaciones venideras (Ramos Gorostiza, 2014).

El tratamiento para adecuar las aguas para el consumo humano es lo que se conoce como potabilización. De manera genérica, el tratamiento de potabilización se divide en 4 fases: primera fase (pretra- 
tamiento, oxidación y desinfección de cabecera); segunda fase (coagulación-floculación y decantación); tercera fase (filtración); y cuarta fase (desinfección residual); a continuación se bombea y se distribuye en la red de abastecimiento.

El objetivo de la potabilización es mejorar la calidad física, química y bacteriológica del agua. Los aspectos básicos que debe cumplir son: higiénicos (que no suponga riesgo para la salud humana); estéticos (eliminación de factores físicos característicos de las aguas tales como color, olor, turbidez y sabor); y económicos (efectos que acorten la vida útil de máquinas e instalaciones).

El agua sin tratamiento alguno es un vector de enfermedades. Muchas surgen sencillamente debido a la falta de agua limpia para el consumo y para lavar los alimentos. Hay cinco tipos de enfermedades infecciosas vinculadas con el agua: transportadas en el agua, arrasadas por el agua, acuáticas, por vectores de insectos acuáticos y enfermedades causadas por prácticas sanitarias deficientes (Global Health and Education Foundation).

Los primeros abastecimientos de aguas en las ciudades surgieron en la segunda mitad del S.XIX ligados a los proyectos de Ensanche de las ciudades. Muchos de ellos no se vieron finalizados hasta el primero tercio del S.XX, incluso algunos hasta después de la Guerra Civil, pese a que las mejoras de contar con un servicio de agua de mayor calidad se aprecian desde el primer momento. Los suministros de agua desde su origen se han enfrentado a diversos problemas, siendo los principales: satisfacer la demanda; los diversos problemas de disponibilidad, tanto espacial como temporal; la correcta planificación del recurso a la hora de combinarlo con otras áreas tales como urbanismo; y por último la explotación racional del recurso junto a los diferentes usos productivos del agua (Rueda, 1994).

\section{OBJETIVOS}

El objetivo del artículo es conocer la historia del abastecimiento de agua en la ciudad de Valencia entre 1860-1910, su importancia sobre la salud y mejora de la calidad de vida de las personas, y su relación con las medidas higiénicas que se desarrollaron durante el primer Ensanche de la ciudad.

\section{RESULTADOS}

\subsection{Calidad de vida previa al Higienismo}

Previamente al Higienismo e industrialización, la provincia de Valencia se encuentra por completo dedicada a la agricultura intensiva. Todas las construcciones y viviendas están adaptadas a las necesidades agrarias. La población urbana de las ciudades se mantenía en un frágil equilibrio entre la vida y la muerte debido a unas condiciones higiénicas deplorables, viviendo hacinados y una alimentación que resultaba escasa, mala y cara. Las ciudades mantenían su población debido fuerte flujo migratorio desde el campo a la ciudad, gracias al cual la ciudad mantenía su índice demográfico en constante crecimiento pese a las epidemias que diezmaban notablemente la población (Corbín, 1996).

Las viviendas se construían con techos bajos (se podían tocar levantando las manos) lo cual era sinónimo de escasa ventilación; los suelos de tierra retenían la humedad debido a la litología arcillosa de la zona, lo cual favorecía la aparición de malos olores e insalubridad. Además cada casa solía tener un corral en el cual se creaban estercoleros donde se amontonaban las deposiciones y residuos orgánicos sobre montones de paja, cuyo fin último era ser utilizados como abono en la agricultura, y que resultaba ser un foco de infección para las personas que habitaban el hogar (Segura, V. y Lassala, E., 1910).

Las poblaciones no cuentan con un sistema de alcantarillado que evacúe los residuos: las deposiciones se amontonaban bien en los estercoleros o en unas fosas rectangulares cavadas en el suelo sin salida. Otro foco de infección procede de los denominados "pozos ciegos" o "pozos negros", a los cuales iban a parar las aguas procedentes de la limpieza (ropa, utensilios cocina, etc.) que llevaban gran cantidad de materia en descomposición. Estos métodos suponen un elevado riesgo de contaminación para pozos y acuíferos (Urteaga, 1985).

No se disponía de agua potable y se abastecían del agua de pozos o directamente del río. Beber agua de estas fuentes supone un riesgo para la salud, ya que esta agua lleva gran cantidad de materia orgánica en descomposición. Además hay que tener en cuenta que en ríos y acequias (que después vierten sus aguas a los ríos) se lavaban ropas y utensilios, se desarrolla la higiene personal e incluso se tiraban a 
ellos animales muertos. Todo esto favorece que el agua que consumida fuese un foco de enfermedades y supusiese un riesgo para su salud.

Para evitar riesgos e infecciones, la Junta de Sanidad aconseja que cada vecino construya en su casa un filtro de agua casero en el cual filtrará toda el agua que se disponga a utilizar. La construcción de los filtros requiere una tinaja de dimensiones regulares, se le hace un agujero en el fondo, sobre el fondo se van echando alternativamente en el orden que se expresan capas de 2 dedos de carbón, cantos rodados del tamaño de garbanzos y arena de río hasta un número de 6 o 8 . Para ser usado, se debe llenar la tinaja de agua potable y la que filtra se la recoge en frascos de gran tamaño, previamente hervidos o lavados con una solución al milésimo de permanganato potásico. Además se debe sedimentar el agua para que deposite las materias orgánicas descompuestas. El agua después de filtrada es la que se debe emplear en tiempos de epidemia para la fabricación de pan, confección de alimentos y para la bebida (Segura, V. y Lassala, E., 1910).

Para paliar y evitar los contagios debidos al consumo del agua, se desarrollan una serie de normas de obligado cumplimiento en caso de epidemia y recomendadas para consumir agua de manera más segura. Estas medidas de carácter higiénico se enumeran en el libro "Estudio higiénico de Algemesí y medios aconsejados por la junta de Sanidad en caso de invasión colérica" tal y como se especifican en la Tabla 2.

Tabla 2. Métodos preventivos de carácter doméstico para evitar contagios.

\begin{tabular}{|r|}
\hline Cada vecino tendrá en su casa un filtro para el agua que empleará para la bebida y confección de alimentos \\
\hline Los utensilios de cocina y mesa deberán hervirse antes de utilizarse \\
\hline Las mesas antes de las comidas deben lavarse con aguas jabonosas y no se deben utilizar servilletas ni manteles \\
\hline $\begin{array}{r}\text { Antes de sentarse a comer, debe enjuagarse la boca con agua filtrada o hervida y lavarse las manos con una solución } \\
\text { de sulfato de cobre al } 12 \text { por } 100\end{array}$ \\
\hline Se procurará una limpieza esmerada de toda la casa, igualmente se blanquearán con cal las cuadras y los corrales \\
\hline Cada vez que se vaya a defecar se echará en el retrete una solución de hipoclorito cálcico (polvos de gas) \\
\hline Se abstendrá por completo de tomar excitantes en general, los alcohólicos son altamente perjudiciales \\
\hline Deben evitarse con cuidado los enfriamientos \\
\hline Podrán tolerarse los refrescos de naturaleza ácida \\
Se cuidará mucho del aseo personal \\
\hline Fuente: Segura, V. y Lassala, E. 19l0.
\end{tabular}

A pesar de las numerosas medidas existentes y de la consciencia colectiva de una necesaria mejora de la higiene pública como medio para detener las infecciones, la población denuncia el abandono desde la capital. Se denuncia el poco apoyo a los servicios benéfico-sanitarios por parte de las autoridades (Segura, V. y Lassala, E., 1910).

\subsection{Ensanche de Valencia de 1884}

Durante todo el S.XIX, la ciudad de Valencia había mantenido constante el índice demográfico debido a las consecuencias de la guerra de la Independencia, la supresión y expulsión de algunas órdenes religiosas y algunas epidemias. Este mantenimiento del índice demográfico es debido al constante flujo migratorio que desborda su capacidad de recepción.

Valencia, antes de la primera mitad del S.XIX, tenía una población de casi 100.000 habitantes en 6.345 casas agrupadas en 47 manzanas dentro del recinto amurallado y su sistema viario está formado por 434 calles y 132 plazas la mayoría sin pavimentar. En este periodo se produce un nuevo dinamismo de la economía debido principalmente a tres factores: una nueva prosperidad agraria, un primer proceso de industrialización (industrias de la madera, mueble y metalurgia) y una revolución de los transportes (trazado de una red ferroviaria y modernización del puerto del Grao), que como consecuencia, acrecientan el constante flujo migratorio desde el interior hasta las ciudades y localidades más prósperas del litoral (Taberner, 1987; Corbín, 1996).

La decisión de ampliar la ciudad es uno de los objetivos más importantes de los municipios y la sociedad en la segunda mitad del S.XIX. El primer proyecto de Ensanche, el cual no se llevó a cabo, presenta 
un gran valor orientativo y tuvo gran transcendencia en los futuros proyectos. Fue el "Proyecto General del Ensanche de la Ciudad de Valencia" de 1858 llevado a cabo por los arquitectos Sebastián Monleón, Antonio Sancho y Timoteo Calvo. Este proyecto se aprobó el 29 de diciembre de dicho año, y al año siguiente el Ayuntamiento de Valencia publicó la correspondiente memoria presentada por el cronista Vicente Boix y el Médico Higienista Manuel Encinas. Este proyecto, previo al Ensanche de Barcelona en 1859, se ideó para dar cabida en la nueva ciudad a los 106.435 habitantes según el censo de 1857 (Taberner, 1897; Corbín, 1996).

Este proyecto presentaba una ampliación del recinto amurallado, previo derrocamiento y la construcción de un nuevo circuito amurallado que incluiría el nuevo crecimiento de la ciudad, salvo en la parte norte, donde se encuentra el río, donde se pensó la instalación de un boulevard. Este proyecto no fue llevado a cabo por: falta de concreción a la hora de definir los medios de las medidas higiénicas, el anacrónico proyecto de la construcción de una muralla cuando la sociedad pedía su demolición, falta de rigor y análisis necesario para poder acometer la reforma de la ciudad, la precaria situación municipal, falta de un marco legal y porque el carácter cerrado del proyecto no fomentaba la capacidad especulativa por lo que la burguesía no participó en él (Taberner, 1987; Corbín, 1996).

En 1854, la Academia de Medicina y Cirugía de Barcelona publica un informe relativo a la influencia que tienen las murallas en la salud de los vecinos indicando que deben demolerse como medida de salubridad importante para el vecindario. Este informe se une al clamor largamente demandado de la creciente población de la ciudad que continúa su imparable crecimiento mientras su proceso de crecimiento se ve bloqueado por la presencia de dichas murallas (Mangiagalli, 2006).

El inicio del derribo de las murallas medievales en la ciudad de Valencia, comenzó tras un pleito contra la Capitanía General que reclamaba la titularidad de los solares provenientes del derribo. Este derribo se inició en 1865, aunque previamente ya se habían hecho derribos parciales, como por ejemplo en 1851, cuando se demolió un tramo de muralla para dar salida al ferrocarril del Grao y Tarragona; o en 1852, cuando se derribó parcialmente otro tramo y se realizó la apertura de una ronda semicircular por el perímetro de la muralla. El derribo de las murallas finalizó en 1891 con la demolición de la Ciudadela. El lugar que ocupaban las murallas fue reconvertido en una ronda exterior que con el tiempo se convirtió en la calle principal: la calle Colón, por la cual circulaban 2 líneas de tranvía. Se produjo un crecimiento de la ciudad hacia el sur, englobando al primitivo arrabal de "Ruzafa" el cual pasó a formar parte de la ciudad de Valencia en 1877 cuando perdió su autonomía y pasó a ser un barrio (Corbín, 1996; Prytherch, D. L., y Boira Maiques, J. V., 2009).

El 22 de diciembre de 1876, se promulga la Ley de Ensanche, y con ella se pone en marcha el primer Ensanche de Valencia que se formalizará en 1884. El proyecto definitivo fue redactado por José Calvo, Luis Ferrere y Joaquín Ma Arnau en 1884. En 1887 dicho proyecto es aprobado por el Real Decreto de julio de 1887.

El Ensanche de 1884 tenía como antecedentes el proyecto de Ensanche de 1858, cuyo sistema vial sirvió de base en la planificación del nuevo trazado, adoptando el sistema de cuadrícula con orientación SE, como en el Ensanche de Barcelona, entre la ronda de circunvalación de la muralla (calle Colón) a la Gran Vía Marqués del Turia. Entre estas grandes vías, hay una calle principal como eje de desarrollo (Cirilo Amorós) seccionada por siete calles (Félix Pizcueta, Pizarro, Hernán Cortés, Isabel la Católica, Jorge Juan, Conde Salvatierra, Grabador Esteve). Como fruto de la aprobación del plan se llevó también a cabo la urbanización y pavimentación de la Gran Vía Marqués del Turia hasta el cauce del río Turia, abriéndose en este tramo una plaza ovalada dedicada a Cánovas del Castillo. Posteriormente se dio un impulso definitivo a esta zona del Ensanche por la Exposición Regional Valenciana y Nacional de 1909 y 1910 (Corbín, 1996).

Este Ensanche también pretende regularizar las manzanas existentes y ensanchar las calles de numerosas zonas que ya estaban construidas, como el Camino al Grau; la conexión con Ruzafa; la instalación de mercados (actual mercado de Rojas Clemente o de Colón); la prolongación de algunas calles con su regularización y nueva construcción, como la zona de la calle Quart o la zona de Convento Jerusalén. Posteriormente, también se realizan reformas interiores como la Avenida del Oeste, la Avenida del Real o el Ensanche de la Plaza de la Reina (Taberner, 1987).

El Ensanche de Valencia, posterior al de Madrid (1860), se diferencia de este último en: el Ensanche de Madrid se hace en plano hipodámico, con calles orientadas en función del viento dominante, la anchu- 
ra de las calle condiciona la altura de los edificios, no conecta el Ensanche con el casco antiguo y no prevé bien el tendido ferroviario. Sin embargo, como el Ensanche de Valencia se basó en el de Barcelona (1859) y en el Proyecto de Ensanche de Valencia de 1858: presentan la misma orientación, ambos disponen las manzanas buscando la máxima exposición a la luz solar, presentan buena unión con el núcleo antiguo y la parte del Ensanche (Cerdá, et al., 1968; Solà-Morales, 1978; Carballo, et al., 2008).

\subsection{Evolución histórica del abastecimiento de agua en Valencia}

El origen del abastecimiento de agua en Valencia surge en 1845 tras la muerte del canónigo Mariano Liñán, el cual deja en herencia 28.000 duros en deuda pública francesa, nombrando como albacea a su hermano. Sobre esta herencia existía una condición: financiar el abastecimiento a la ciudad para que comenzasen las obras antes de un año, si no fuese así, el dinero pasaría a la Beneficencia. Para llevar a cabo la construcción de este proyecto se crea una Comisión formada por: el Ayuntamiento de Valencia, la Sociedad Económica de Amigos del País y el hermano del canónigo Liñán. Esta comisión solicita a la reina Isabel II la realización del abastecimiento a la ciudad. La reina concede el permiso para crear la red y la planta de abastecimiento para la ciudad (EMIVASA, 2007). Este hecho se recoge en la prensa de la época como una gran mejora que elevará a Valencia a una ciudad moderna junto a otra serie de medidas como el ferrocarril o el establecimiento de coches fúnebres (Boix, 1845a).

Tras varios estudios se decide que la toma se realice en el río Turia. Previamente a este proyecto, existían otros planes que pretendían traer agua desde pueblos del interior o elevar agua de pozos y repartirla por la ciudad en distintas fuentes. Ambos proyectos fueron desestimados por la Sociedad Económica del País debido a que no garantizaban el suministro adecuado, ni en calidad ni cantidad. Dicha comisión dictamina la necesidad de traer agua a Valencia, que se debe tomar dicha agua del río Turia previamente tratada (Boix, 1845b).

El proyecto lo realiza el ingeniero Calixto Santa Cruz, director de la ETSICCP (Escuela Técnica Superior de Ingenieros de Caminos, Canales y Puertos) de Madrid, y la obra es dirigida por el ingeniero Ildefonso Cerdá con la colaboración de D. Leodegario Marchessaux. Una vez realizado el proyecto, se ve que es insuficiente la cantidad económica legada por el canónigo, la cual suponía aproximadamente el $10 \%$ de la obra, ascendiendo a más de 6 millones de reales: 4 millones para la construcción del azud, los tratamientos de potabilización y las traídas de agua; y otros 2 millones para su abastecimiento en la ciudad (Boix, 1845c; EMIVASA, 2007).

Para ello D. José Campo, Marqués de Campo, entonces Alcalde de Valencia, crea una Sociedad Anónima donde particulares aporten dinero que se retornaría mediante impuestos en la ciudad. El sistema para conseguir la financiación se basa en unos impuestos en aduanas sobre el trigo y otros alimentos básicos (Boix, 1846). Con el tiempo, D. José Campo deja la alcaldía y se erige presidente de la "Conducción de agua Potable a la ciudad de Valencia S.A", cuya Junta Directiva estaba integrada por: José Campo (Presidente), el Marqués de Tremolar, Tomás Liñán (hermano del canónigo), Lucas Yánez, Joaquín Forés y Peregrín Caruana.

Entre 1846-1850 se construye el azud de "La Presa", una balsa de decantación y un acueducto que llega hasta el Arquillo. Desde el Arquillo parten dos tuberías de Diámetro Nominal (DN) de $355 \mathrm{~mm}$ que llegan hasta el Depósito General de la Cruz de Mislata (actual Museo Histórico de la Ciudad de Valencia). Desde este depósito salen las primeras tuberías de agua potable que abastecen la ciudad por la Calle Quart y la Calle Caballeros, abasteciendo una media docena de fuentes bebedero: fuente de la Plaza del Negrito, antigua Plaza de Calatrava, etc. En el periódico El Fénix de 1848 con fecha de 30 de enero, se detalla la visita que los periodistas hacen a la obra, detallando cómo va su ejecución, dónde se va instalar la planta potabilizadora (G. C., 1848).

Dado que el tratamiento y distribución del agua potable es complejo y con muchos gastos de operación y mantenimiento, se otorga concesión independiente a la explotación del acueducto a D. Rafael Sociat. De este modo el abastecimiento se divide entre dos empresas: la primera cuyo presidente es D. José Campo se dedica a la captación y tratamiento del agua (gestión de agua en alta); y la segunda a cargo de D. Rafael Sociat se centra en la distribución (gestión de agua en baja). La ejecución de este proyecto supuso pasar de consumir agua de pozos a un servicio que abastecía 100 litros por habitante y día (Guardia, 2012). 
Entre 1850 y 1878 se observa que la demanda crece en la ciudad. El sistema de captación, tratamiento y distribución es insuficiente para abastecer a la población. Desde el ayuntamiento debido a esta necesidad social que la propia sociedad demanda, pide a la empresa que aumente tanto en calidad y cantidad el agua que suministra a la ciudad, ya que la que llega es insuficiente en calidad y en presión. Para solventar esta complicación, la ciudad de Valencia hace una fuerte inversión en mejorar los filtros y la red de la ciudad para subsanar los problemas de calidad y pérdidas de las aguas en la red de abastecimiento. En 1859, la ciudad está de nuevo en obras por la canalización de las aguas potables, cuyas conducciones superaban los 4.000 metros de longitud (Taberner, 1987). Estas medidas son insuficientes y tardías, ya que en 1884 y 1885 suceden epidemias de cólera muriendo 30.000 personas (EMIVASA, 2007)

A finales de 1885, nace un nuevo proyecto para el incremento de caudal, presión y calidad del agua potable en un intento de que no se repitan de nuevo estos episodios de epidemia. Para ello, se publica un concurso para realización de una nueva obra para mejorar la captación y el tratamiento del agua potable, con una concesión de 40 años. Se adjudica a Fernando de Vicente y Charpentier, y la obra se ejecuta en 1888. Ésta consiste en el depósito de San Onofre en Quart de Poblet, tubería DN 600 mm en el tramo San Onofre-Arquillo, balsas de decantación en "La Presa" y mejoras en los filtros de Manises. Este periodo coincide con el Ensanche de Valencia de 1884. En todos los proyectos de Ensanche, tanto en Madrid como en Barcelona, el principal problema a resolver es lograr un suministro de agua continuo y con la dotación suficiente (Guardia, 2012).

El problema de insuficiencia en el abastecimiento de agua persiste hasta la finalización de los Planes de Ensanche. La ciudad sigue creciendo a un ritmo muy acelerado, por lo que este incremento de caudal no es suficiente para abastecer, tanto en calidad como cantidad, a todos los habitantes de la ciudad de Valencia (Ayuntamiento de Valencia, 1890). Por ello, la población se ve obligada a consumir aguas de pozos lo que da origen a una nueva epidemia de cólera en 1890. Esta epidemia generó gran polémica tras la mala predicción del aumento de población para abastecer en la ciudad tras el nuevo proyecto de Fernando de Vicente y Charpentier. Este último abandona la concesión y se la cede a "Aguas Potables y Mejoras de Valencia S.A" en 1890. De nuevo una única empresa privada controla el tratamiento y distribución del agua potable en la ciudad de Valencia.

Tras 10 años de funcionamiento imperfecto y muchos problemas, el modelo de abastecimiento de aguas de la ciudad resulta poco efectivo. A partir de 1896 se realizan numerosos controles de calidad por parte del Ayuntamiento, los cuales evidencian las malas condiciones del servicio y la necesidad de ponerle remedio. Como respuesta se realizaron diferentes inversiones para ampliar los filtros y mejorar la red de abastecimiento (Ayuntamiento de Valencia 1896; Ayuntamiento de Valencia 1899). A finales del S. XIX, Valencia como el resto de ciudades españolas, presenta los principales problemas que presenta el abastecimiento del agua a final del S.XIX, los cuales se pueden resumir en: la necesidad de adecuar el servicio a la demanda creciente y no cubierta; mejorar las condiciones técnicas del proceso de potabilización y abastecimiento de agua; y por último afrontar las deficiencias higiénicas de y salud pública que se denuncian (Rueda 1994).

Finalmente en 1900, debido a la falta de escasez de presión y la ineficiencia del tratamiento, "Aguas Potables y Mejoras de Valencia S.A" y la ciudad de Valencia, deciden crear un abastecimiento completamente nuevo. En 1901se presenta la Memoria de Presupuestos relativos a este nuevo abastecimiento con su memoria justificativa (Ayuntamiento de Valencia 1900; Ayuntamiento de Valencia 1901). Este nuevo abastecimiento coincide con el segundo ensanche, que ampliaba el anterior y extendía la ciudad hasta el antiguo Camino de Tránsitos (avenida de Pérez Galdós y Peris Valero) bajo la dirección de los arquitectos Francisco Mora y Vicente Pichó en 1907.

El proyecto se aprueba en 1904. La inversión se financia con una nueva concesión a 90 años, que finalizó en marzo de 2003. Las obras se ejecutan entre 1904 y 1908 y consisten en: un nuevo sistema de potabilización (revólveres Anderson); la instalación de filtros en "La Presa"; la construcción de la sala de bombas (hoy en día en servicio); la construcción del primer depósito de Collado de planta circular; la conducción en presión desde "La Presa" hasta Valencia; y la renovación de gran parte de la red interior de la ciudad.

La historia de los abastecimientos en este periodo es similar tanto en Valencia, Madrid como Barcelona. A mediados del S.XIX se genera un sistema de abastecimiento moderno para dotar de agua potable mediante fuentes bebedero distribuidas por la ciudad. Posteriormente, cuando los Ensanches surgen para adaptar las ciudades a los retos que se enfrentaban en la época, los abastecimientos son insuficientes para dar servicio a la población y los nuevos barrios. Para solucionar estos problemas a finales del S.XIX y prin- 
cipios del S.XX se tiene que invertir para crear nueva red de abastecimiento, mejorar la existente y unirla con los nuevos barrios, además de mejorar el tratamiento de potabilización (Rueda, 1994; EMIVASA, 2007; Guardia, 2012).

La historia de los abastecimientos de Valencia, Madrid y Barcelona presenta un hecho común: es la iniciativa privada es quien atiende un servicio público como es el abastecimiento de agua. En Barcelona por ejemplo, la pasividad municipal da lugar a la aparición de numerosas empresas privadas como: La Sociedad de Crédito y Fomento de Barcelona (que abasteció de agua para sus fines inmobiliarios); Aguas Potables de Barcelona y la Compañía de Aguas de Barcelona (sociedad con capital franco-belga bien capitalizada y con amplia experiencia), siendo esta última la que a finales del S. XIX mediante recursos financieros aportados por la Société Lyonnaise des Eaux, constituye la Sociedad General de Aguas de Barcelona comprando al resto de pequeñas empresas y monopolizando el servicio. El caso de Madrid es más singular: es la Corona quien acomete la obra de abastecimiento justificándolo como que su ejecución es necesaria en base del Interés General para ante la incapacidad del Ayuntamiento y el desinterés de la iniciativa privada, posteriormente se da a una empresa privada (como en los casos anteriores), pero dicha empresa quebró y volvió a ser parte del Estado (Rueda, 1994; Guardia, 2007).

\subsection{Cambios en la calidad de vida tras el Higienismo}

El uso y aplicación de los de los nuevos inventos y avances a la vida cotidiana como: el alumbrado de gas, el telégrafo, el tranvía, la electricidad o el ferrocarril, suponen una mejor calidad de vida para los ciudadanos. Las viviendas se continúan construyendo en base a las necesidades de la agricultura, pero comienzan a tenerse en cuenta los principios Higienistas: el suelo se pavimenta con una capa de grava apisonada que mejora la salubridad y evita la permanente humedad, los techos se elevan y las paredes se blanquean con cal, la ventilación se facilita con numerosas ventanas y se observa una mejora en la decoración tanto interior como exterior de las viviendas (Segura, V. y Lassala, E., 1910).

Otras innovaciones constituyen adelantos higiénicos que mejorarán la salud pública: la introducción del alcantarillado, que deriva las aguas sucias de la ciudad y evita las filtraciones de los efluentes domésticos, termina con los pozos negros o ciegos, que eran foco permanente de infecciones; el adoquinado de las calles, el cual permitió que en episodios de lluvia las calles no se convirtieran en lodazales que impedían el tránsito y que tenían olor pestilente por la putrefacción de las materias y eran foco de enfermedades.

El abastecimiento y distribución del agua que surge durante el Higienismo consiste en la conducción del agua mediante cañerías subterráneas o acueductos a depósitos. Estos depósitos se encuentran a una altura de manera que las aguas puedan ser distribuidas por todos los pisos. El llenado de estos depósitos se realiza mediante bombas si de manera natural no se puede hacer. Destacar que desde este movimiento se hace ya una diferencia entre el uso del agua en las ciudades: aguas de alimentación o potables; y aguas de servicio municipal. Las primeras son las que van canalizadas y se tratan mientras que las segundas se toman directamente de ríos y canales (Paulier, 1881; Segura, V. y Lassala, E., 1910).

El agua canalizada llega a las poblaciones con las siguientes características: "es inodora, incolora, de sabor agradable, cuece bastante bien las legumbres, y está casi desprovista de materia orgánica nociva" (Segura, V. y Lassala, E., 1910). Las aguas potables de los depósitos, no están completamente puras ya que "contienen en suspensión materias extrañas". Por ello recomienda su filtrado mediante cualquier sistema, como por ejemplo: tabiques perforados, filtros de areniscos, filtro de Vedel-Bernard, filtro de fieltro, etc. (Paulier, 1881). Estas "materias extrañas" pueden ser debidas a tratamientos ineficientes, pero principalmente a la deficiente red de distribución. Aparte de la gran cantidad de fugas que presentaban, siendo estas la entrada de contaminantes orgánicos; los materiales de las tuberías reaccionaban con el agua, añadiendo contaminantes químicos al agua. Inicialmente utilizan tuberías de plomo, las cuales desde el principio son polémicas ya que eran origen de "intoxicación saturnina" (Paulier, 1881).

Ya desde el inicio la calidad de las aguas se legisla dada su importancia para la salud pública. La primera ley que establece valores sobre la calidad de las aguas es la Ley de Sanidad de 1855 como medio para combatir las posibles epidemias que puedan surgir por tomar agua no tratada. Un dato llamativo de esta ley es que establece que en caso de epidemia el agua debe ser hervida antes de consumirse. Incluso para la elaboración de comidas debe utilizarse únicamente agua hervida o filtrada a través de unos filtros rudimentarios hechos manualmente a base de carbón, cantos rodados y arena de río como medida de contención de la epidemia. 
La siguiente referencia a la calidad del agua se encuentra en la Instrucción General de Sanidad de 1904, donde se menciona la necesidad de costear y mantener laboratorios municipales para dar respuesta al servicio de desinfección de agua, sobre esto reincidirá la Real Orden de 1908 indicando la obligación de los municipios de más de 10.000 habitantes de tener un laboratorio.

\section{CONCLUSIÓN}

El siglo XIX marca el inicio de una revolución que cambiará radicalmente la forma de vida de la población y terminará con las elevadas tasas de mortalidad, propiciando un crecimiento vegetativo de la población. Los factores desencadenantes se sitúan en los inicios de la Revolución Industrial, a raíz de la cual la vida en el campo se desestructuró y los campesinos se ven obligados a migrar hacia las ciudades, las cuales comienzan a crecer sin ningún tipo de control ni planificación previa. Los migrantes se agrupan en barrios carentes de servicios y en viviendas hacinadas sin ventilación y con unas condiciones de vida deplorables. La mala calidad de vida favorece la aparición de enfermedades y la población es constantemente diezmada por epidemias. Como consecuencia, las tasas de mortalidad son muy elevadas.

Esta situación es la base de una revolución que se desarrolló en las ciudades a favor de la promulgación de avances en la calidad de vida que mejoraran las condiciones de vida de la población y la salud en general. El Higienismo como movimiento tuvo gran importancia y en base a él se diseñaron las nuevas ciudades, teniendo en cuenta la ventilación de las casas, el adoquinado de las calles, la construcción de alcantarillados, etc. Uno de los puntos clave de este movimiento era el tratamiento y distribución del agua, como medio para evitar epidemias y enfermedades. El poder consumir agua sin que supusiese ningún riesgo para la salud humana supuso un antes y un después en la calidad de vida de las personas.

La ciudad de Valencia es un claro ejemplo de la importancia de este proceso como medio de control de epidemias. En este siglo la ciudad se encuentra recluida dentro del recinto amurallado, sin red de distribución ni agua potable libre de riesgos sanitarios. El origen del abastecimiento de agua potable comienza en Valencia gracias a capital privado (herencia del canónigo Mariano Liñán). Para poder financiar la totalidad del coste de la obra, el entonces alcalde de Valencia D. José Campo, Marqués de Campo, crea una sociedad anónima "Conducción de agua Potable a la ciudad de Valencia S.A"

Inicialmente, este abastecimiento va creciendo y mejorando al ritmo que va creciendo la ciudad. A partir del Ensanche 1884 el abastecimiento de agua potable se queda obsoleto, dando un servicio insuficiente, de baja calidad y que presenta riesgos para la salud del consumidor. Finalmente, al principio del S.XX se decide hacer un nuevo abastecimiento para solucionar los problemas que presentaba la ciudad.

\section{REFERENCIAS}

Alcaide González, R. (1999). La introducción y el desarrollo del Higienismo en España durante el siglo XIX: Precursores, continuadores y marco legal de un proyecto científico y social. Scripta Nova, 50. Recuperado de http://www.ub.edu/geocrit/sn-50.htm

Ayuntamiento de Valencia (1890). Estudios para el mejoramiento de las aguas potables de Valencia. Valencia: Ayuntamiento de Valencia.

Ayuntamiento de Valencia (1896). La Junta Municipal de Sanidad hace presente al Ayuntamiento de Valencia el peligro que corre el vecindario por las malas condiciones que suministra la empresa y la urgentísima necesidad de ponerle remedio.Valencia: Ayuntamiento de Valencia.

Ayuntamiento de Valencia (1899). Comprobación de las cualidades y cantidad del agua potable que suministra la empresa concesionaria de la explotación del servicio. Valencia: Ayuntamiento de Valencia.

Ayuntamiento de Valencia (1900). Determinación de los medios que pueda utilizar el Ayuntamiento para obligar a la Sociedad Aguas Potables a dar buen servicio. Valencia: Ayuntamiento de Valencia.

Ayuntamiento de Valencia (1901). Transcripción en el registro de aprovechamiento de aguas públicas a Valencia para el abastecimiento de aguas potables. Valencia: Ayuntamiento de Valencia.

Bairoch, P. and Goertz, G. (1986). Factors of Urbanization in the Nineteenth Century Developed Countries: A Descriptive and Econometric Analysis. UrbanStudies, 23, 285-305. Retrieved from https://deepblue. lib.umich.edu/bitstream/handle/2027.42/68656/10.1080_00420988620080351.pdf 
Barona Vilar, C. (2002). Organización sanitaria y de la higiene pública en la provincia de Valencia (18541936). Valencia: Universidad de Valencia.

Boix, V. (1845a). Crónica de la Quincena. El Fénix, (6), 7.

Boix, V. (1845b). Aguas Potables. El Fénix, (7), 75-77.

Boix, V. (1845c). Aguas Potables. El Fénix, (8), 88-89.

Boix, V. (1846). Crónica de la Quincena. El Fénix, (19), 222.

Carballo, B., Pallol, R. y Vicente, F. (2008). El Ensanche de Madrid Historia de una capital. Madrid: Editorial Complutense S.A.

Cerdá, I., Barrera de Irimo, A., Estapé, F., 1923-2012, \& Instituto de Estudios Fiscales (España). (1968). Teoría general de la urbanización y aplicación de sus principios y doctrinas a la reforma y Ensanche de Barcelona. Barcelona: Instituto de Estudios Fiscales.

Colegio de Caminos Canales y Puertos de Alicante. (1991). El saneamiento de Alicante en 1905: Ciencia, técnica e Higienismo. Facsímil de la Memoria del Proyecto de Saneamiento del Puerto de Alicante. Alicante: Colegio de Caminos Canales y Puertos de Alicante

Corbín, J. L. (1996). El Ensanche Noble de Valencia: entre Colón y la gran Vía Marqués del Turia. Valencia: Federico Domenech, S.A

Dopico, F., \& Rowland, R. (1990). Demografía del censo de Floridablanca. Una aproximación. Revista de Historia Económica - Journal of Iberian and Latin American Economic History, Año 8(3), 591-618. Recuperado de http://e-archivo.uc3m.es/bitstream/handle/10016/1860/RHE-1990-VIII-3-DopicoRowland.pdf;jsessionid=922DF06CB3E79972A06BE07DF6F60060? sequence $=1$

EMIVASA. (2007). Historia de las plantas potabilizadoras de Valencia. Material no publicado.

G. J. (1848). Conducción de aguas a Valencia. El Fénix, (122), 203.

Global Health and Education Foundation. Recuperado de http://www.drinking-water.org/html/es/ Treatment/Water-Related-Diseases.html

Guardia, M. (2012). La revolución del agua en Barcelona, 1867-1967. Claves Del Mundo Contemporáneo. "Claves Del Mundo Contemporáneo Debate E Investigación XI Congreso de La Asociación de Historia Contemporánea Granada, 12-15 de Septiembre de 2012," 1-14.

Hijano Perez, A. (2013). The township and municipal services in nineteenth century Spain. Ayer: Revista de Historia Contemporánea, (90), 141-166.

Mangiagalli, S. A. (2006). Barcelona 1854-1856: Crónicas Del Ensanche Reflexiones De Antonio Brusi Ferrer. ACE: Architecture, City and Environment, 1, 29-45. Recuperado de http://revistes.upc.edu/ojs/ index.php/ACE/article/view/2338\#

Paulier, A. B. (1881). Manual de Higiene Pública y Privada, Traducido por Arnau Clemente, Álvaro y anotado por Gómez, Constantino. Valencia : Pascual Aguilar

Prytherch, D. L., Boira Maiques, J. V. (2009). City profile: Valencia. Cities, 26(2), 103-115. Doi: http://doi. org/10.1016/j.cities.2008.11.004

Ramos Gorostiza, J. L. (2014). Edwin Chadwick, el movimiento británico de salud pública y el Higienismo español. Revista de Historia Industrial, 23(55), 11-38. Recuperado de http://www.raco.cat/index.php/ HistoriaIndustrial/article/view/280098/367800

Rueda Laffond, J. C. (1994). El Agua en Madrid. Datos para la historia del Canal Isabel II 1851 - 1930. Madrid: Fundación Empresa Pública.

Segura, V., \& Lassala, E. (1910). Estudio higiénico de Algemesí y medios aconsejados por la junta de Sanidad en caso de invasión colérica. Sueca: Junta de Sanidad

Solà-Morales, M. (1978) Los Ensanches (I). El Ensanche de Barcelona. Barcelona: Ediciones de la Escuela Técnica Superior de Arquitectura de Barcelona

Taberner, F., Institució Valenciana d'Estudis i Investigació, \& Col-legi Oficial d'Arquitectes de la Comunitat Valenciana. (1987). Valencia entre el Ensanche y la reforma interior. ( No. 2.). València: EdicionsAlfons el Magnánim.

Urteaga, L. (1985). Higienismo y ambientalismo en la medicina decimonónica. Dynamis (Granada, Spain), 5-6, 417-425. Recuperado de http://www.raco.cat/index.php/Dynamis/article/view/121798 